\title{
Biologics to Improve Healing in Large and Massive Rotator Cuff Tears: A Critical Review
}

This article was published in the following Dove Press journal:

Orthopedic Research and Reviews

\author{
Brandon T Goldenberg (iD) \\ Lucca Lacheta ${ }^{1,2}$ \\ Travis J Dekker ${ }^{3}$ \\ James D Spratt $\mathbb{D}^{\prime}$ \\ Philip C Nolte $\mathbb{D}^{\prime}$ \\ Peter J Millett ${ }^{1,4}$
}

'Steadman-Philippon Research Institute, Vail, CO 81657, USA; ${ }^{2}$ Center for Musculoskeletal Surgery, Charitè Universitaetsmedizin Berlin, Berlin, Germany; ${ }^{3}$ Department of Orthopaedic Surgery, Eglin Air Force Base, Elgin, FL, USA; ${ }^{4}$ The Steadman Clinic, Vail, CO 81657, USA
Correspondence: Peter J Millett

I8I West Meadow Drive Suite 1000, Vail, CO 81657, USA

Tel +19704795876

Fax +19704799753

Email drmillett@thesteadmanclinic.com

\begin{abstract}
Large and massive rotator cuff tears have the highest risk of retear. Common biologic modalities that can potentially reduce the retear rate and improve healing include platelet-rich plasma (PRP), scaffolds, and mesenchymal stem cells (MSCs). PRP has been studied for its role in improving rotator cuff healing and results of randomized controlled trials and meta-analyses show mixed results. Most studies in large and massivge tears show that PRP decreases the retear rate, but the connection between structural integrity and clinical outcomes is still unknown. Extracellular matrix (ECM) and synthetic scaffolds can increase healing in augmentation and bridging repair. Acellular dermal allografts have shown better healing rates and outcomes than xenografts in meta-analyses. Synthetic scaffolds augmented with bone marrow-derived stem cells have only been studied in vitro but are promising for the combination of mechanical stability and induction of a biological response. Superior capsule reconstruction is an exciting type of interposition graft reconstruction that has shown favorable early clinical outcomes for large and massive tears. Bone marrow-derived stem cells and adipose-derived stem cells improve the biomechanical characteristics of tendon repair and enhance the histological findings of the healing process in animal studies. However, evidence from human studies is lacking, especially in patients with large and massive tears. In summary, there are many biological options to augment rotator cuff repair in patients with large and massive tears. Due to mixed results and a lack of standardization in high-quality studies, we cannot recommend PRP at this time as an adjunct to rotator cuff repair. Both ECM and synthetic scaffolds, as well as SCR, can be used, especially in situations where native tendon is compromised, and additional mechanical augmentation is needed. Stem cells have been the least studied to date, so it is difficult to give recommendations for or against their use at this time.
\end{abstract}

Keywords: biologics, large rotator cuff tears, massive rotator cuff tears, platelet-rich plasma, scaffolds, mesenchymal stem cells

\section{Introduction}

The surgical management of large and massive rotator cuff tears poses technical and biologic challenges to the treating surgeon. Many patients with tears of this size suffer from chronic sequelae, such as tendon retraction and tendon loss, as well as muscle atrophy and fatty infiltration of the muscle, all of which create a technically difficult and biologically challenging environment for successful repair. ${ }^{1}$ At the tissue level, the biological environment becomes compromised as chronically damaged rotator cuff tendon suffers from reduced cellularity and vascularity, greater collagen disorganization, and lower collagen concentration. ${ }^{2}$ Even after surgery, repaired tissue undergoes reactive fibrosis, which contributes to the lack 
of healing and high rates of structural failure or retears. ${ }^{3,4}$ Recent reports of structural failure rates after arthroscopic repair of large and massive rotator cuff tears can be up to $94 \%{ }^{5}$ with massive tears comprising $80 \%$ of recurrent tears. $^{6,7}$ While patients can do well clinically, retears are associated with less satisfactory outcomes and the need for additional procedures. ${ }^{8}$

The biomechanics of rotator cuff repair have been studied extensively over the last two decades and in many cases have been improved through better surgical techniques and better repair constructs. ${ }^{9-11}$ In order to optimize the integrity of healing and to reduce structural failure, researchers more recently have started to focus on improving the healing environment by modifying the biology following rotator cuff surgery. ${ }^{12}$ Biologic adjuvants such as PRP, scaffolds, and stem cells have been investigated as a means to enhance healing at the tendon-to-bone interface and to improve muscle and tendon quality. Since large and massive rotator cuff tears are the most challenging tear pattern to treat, it is in this patient population that biologics could potentially help to enhance healing and improve structural integrity. In this paper, we aim to provide an overview of the most common biological augmentation options and to evaluate the most recent and highest quality evidence on their effectiveness in the treatment of large and massive rotator cuff tears.

\section{Platelet-Rich Plasma (PRP)}

PRP is a whole blood fraction containing high platelet concentrations that, when activated, releases growth factors to aid in tissue repair. ${ }^{13}$ The current literature discusses a wide variety of biological adjuvants to augment healing, and PRP has been studied both for its potential benefits in augmenting surgery and in non-operative management. For example, PRP can stimulate tendon to bone healing due to its high concentrations of growth factors that work to influence cell migration, tissue maturation, ${ }^{14}$ and inflammation. ${ }^{15}$ Specifically, TGF-B3 increases rotator cuff repair strength by decreasing the production of IL-1B in diseased human tissue and diminishes IL-1B's proinflammatory effects. ${ }^{16,17}$ Moreover, one in vitro study showed PRP increases the number of rotator cuff fibroblasts, which can accelerate tendon-bone remodeling. ${ }^{18,19}$ Formulations containing high concentrations of platelets can induce neoangiogenesis through VEGF and can provide a temporary matrix to aid in tissue remodeling. ${ }^{14}$ However, due to the additional upregulation of matrix metalloproteinases (MMPs), it is theorized neoangiogenesis may overall be detrimental to tendon healing. ${ }^{20}$

The beneficial effects on healing and clinical outcomes of using PRP specifically in large and massive tears have been inconsistent in higher quality clinical studies. For example, Warth et al conducted a meta-analysis of Level I and Level II studies and found that among initial tear sizes greater than $3 \mathrm{~cm}$ in the anterior-posterior direction, those treated with PRP had a statistically significant reduction in retear rate after double-row repair compared to controls $(25.9 \%$ vs $57.1 \%, \mathrm{p}=0.046)$. Though there was an overall gain in Constant score when PRP was placed at the tendon-bone interface rather than over the surface of the repaired tendon $(p=0.046)$, it should be noted that no statistically significant differences in clinical or structural outcomes between PRP+ and PRP-groups were found for all included studies, which consisted of tears of all sizes. ${ }^{21}$ Similarly, in a randomized controlled trial, Pandey et al followed 102 patients with medium $(1-3 \mathrm{~cm})$ and large $(3-5 \mathrm{~cm})$ posterosuperior rotator cuff tears who underwent single-row repair and a minimum follow up of 2 years. Large tears that were augmented with PRP at the time of repair showed statistically significant $(p=0.035)$ lower retear rates when compared to nonaugmented controls (4\% vs 20\%). They also showed that the PRP group had increased vascularity at the repair site on ultrasound at 3 months postoperatively and in the peribursal tissue, an effect which lasted at least until 12 months postop. Furthermore, the PRP group showed a significant increase in the University of California-Los Angeles (UCLA) scores at 12 months postoperatively $(\mathrm{p}<0.05)$ and Constant scores 24 months postoperatively $(p<0.05) .^{22}$

In another study, Jo et al conducted a randomized clinical trial with PRP augmentation for large and massive rotator cuff repairs. Among 48 patients at minimum of 9 months MRI follow-up, the PRP group had a retear rate of $20 \%$, whereas the retear rate was $55.6 \%$ in the control group $(\mathrm{p}=0.023)$. However, there was no significant difference in clinical outcomes between the two groups. ${ }^{23}$ The authors concluded that better structural integrity in the PRP group might suggest improved clinical outcomes at longer term follow-up, but the relationship at the present time is still unknown. In a more recent randomized clinical trial by the same group that was restricted to medium to large tears $(1-5 \mathrm{~cm})$, the PRP treated group had a significantly lower retear rate $(3.0 \%$ vs $20.0 \% \mathrm{p}=0.043)$ than the control and a significantly larger increase in cross-sectional area of the supraspinatus at 1-year postop compared to preop values. 
The authors concluded that PRP dramatically improved postoperative healing and attributed their good results to their leukocyte-poor formulation. ${ }^{24}$ Further reasoning can be supported by basic science studies showing that high concentrations of leukocytes in PRP can cause a greater acute inflammatory response $\mathrm{e}^{25}$ and increased activity of matrix metalloproteinases to enhance catabolic signaling. ${ }^{26}$

On the contrary, a randomized controlled trial performed by Antuna et al showed PRP has no advantage in increasing healing in large and massive tears. Out of 28 total patients with 1-year MRI follow-up, the rate of retear in the PRP group was $71 \%$ whereas it was $64 \%$ in the control group, with no statistically significant differences found. Also, no significant differences were found in Constant and DASH scores at 1 year. $^{27}$ We believe this to be a study of lower quality because the details of their PRP formulation were not explicitly reported. The only information provided was $6 \mathrm{~mL}$ of PRF (Vivostat PRF ${ }^{\circledR}$, Alleroed, Denmark) were used.

In many meta-analyses studying the efficacy of PRP in all sizes of tears, there also has been a discordance of results with no overall clinical superiority of PRP versus untreated controls. $^{21,28-33}$ Saltzman et al conducted a systematic review of meta-analyses and concluded that PRP used at the time of arthroscopic rotator cuff repair did not improve overall retear rates or outcome scores. On subgroup analysis they found significant superiority of PRP treatment in patients with small and medium-sized tears versus large and massive, in the setting of a double-row repair, and when PRP was applied at the tendon-bone interface in solid, over liquid, formulation. ${ }^{34}$ The authors noted that the results could be due to less load on the anchor points in small to medium tears compared to large and massive tears. Also, better biomechanical stability and vascularization in small to medium tears might allow for enhanced incorporation of growth factors to affect the healing process. ${ }^{35} \mathrm{We}$ believe the results of this review should be interpreted with caution. As the authors further state, there was a substantial amount of heterogeneity in terms of surgical fixation technique, performance of acromioplasty at the time of surgery, size of rotator cuff preoperatively, type of imaging used to assess retear occurrence, and preparation, formulation, and means of administration of PRP. ${ }^{34}$

Given the high rates of retear after arthroscopic repair of large and massive tears, there is an opportunity to find and utilize an effective formulation of PRP to improve healing and clinical outcomes. In studies limited to large and massive tears, some randomized controlled trials report PRP's structural healing potential. However, these RCTs lack extended follow-up. Also, as shown by the meta-analyses presented here, PRP's effectiveness is still up for debate. Thus, there is insufficient evidence to suggest a recommendation for its use. A recent 2016 AAOS consensus statement identified several obstacles to the advancement of PRP therapies and made recommendations on how future research efforts should be directed to overcome these challenges. Reasons most likely stem from a failure of many studies to include sufficient experimental detail of their PRP formulations. This has led to a wide variability of preparation protocols and formulations (Table 1), and thus the

Table I Level I Studies of PRP

\begin{tabular}{|c|c|c|c|c|}
\hline $\begin{array}{l}\text { Study (Year) } \\
\text { (RC Size) }\end{array}$ & $\begin{array}{l}\text { Platelet } \\
\text { Concentration }\end{array}$ & $\begin{array}{l}\text { WBC } \\
\text { Concentration }\end{array}$ & $\begin{array}{l}\text { RBC } \\
\text { Concentration }\end{array}$ & PRP Preparation Protocol \\
\hline $\begin{array}{l}\text { Pandey et al } \\
(2016)(\mathrm{med} / \\
\text { large })^{22}\end{array}$ & $\begin{array}{l}\text { Platelets: } 474.00 \\
\times 10^{5} / \mu \mathrm{L} \pm 0.3\end{array}$ & $\begin{array}{l}\text { WBCs: } 0.004 \\
\times 10^{3} / \mu \mathrm{L} \pm 0.001\end{array}$ & $\begin{array}{l}\text { RBCs: } 0.000001 \\
\times 10^{6} / \mu \mathrm{L} \pm \\
0.000001\end{array}$ & $\begin{array}{l}50 \mathrm{~mL} \text { blood drawn, citrate phosphate dextrose added to blood in 7:1 } \\
\text { ratio; stored up to a day at room temperature; } 10 \% \text { calcium chloride } \\
\text { mixed in 5:I ratio to activate PRP; applied over repair site }\end{array}$ \\
\hline $\begin{array}{l}\text { Jo et } \mathrm{al}^{23} \\
(2013) \text { (large/ } \\
\text { massive) }\end{array}$ & $\begin{array}{l}\text { Platelets: } 1096.48 \\
\times 10^{3} / \mu \mathrm{L} \pm 255.40\end{array}$ & $\begin{array}{l}\text { WBCs: } 0.04 \\
\times 10^{3} / \mu \mathrm{L} \pm 0.06\end{array}$ & $\begin{array}{l}\text { RBCs: } 0.18 \\
\times 10^{3} / \mu \mathrm{L} \pm 0.06\end{array}$ & $\begin{array}{l}\text { Blood drawn I day prior to surgery and stored at room temperature; } \\
0.3 \mathrm{~mL} \text { of } 10 \% \text { calcium gluconate added to } 3 \mathrm{~mL} \text { of PRP; PRP placed at } \\
\text { tendon-bone interface }\end{array}$ \\
\hline $\begin{array}{l}\text { Jo et } \mathrm{al}^{24} \\
(2015)(\mathrm{med} / \\
\text { large) }\end{array}$ & $\begin{array}{l}\text { Platelets: } 1218.40 \\
\times 10^{3} / \mu \mathrm{L} \pm 334.69\end{array}$ & $\begin{array}{l}\text { WBCs: } 0.04 \\
\times 10^{3} / \mu \mathrm{L} \pm 0.03\end{array}$ & $\begin{array}{l}\text { RBCs: } 0.14 \\
\times 10^{3} / \mu \mathrm{L} \pm 0.04\end{array}$ & $\begin{array}{l}\text { Blood drawn I day prior to surgery and stored at room temperature; } \\
0.3 \mathrm{~mL} \text { of } 10 \% \text { calcium gluconate added to } 3 \mathrm{~mL} \text { of PRP; PRP placed at } \\
\text { tendon-bone interface }\end{array}$ \\
\hline $\begin{array}{l}\text { Antuna et } \mathrm{al}^{27} \\
\text { (large/ } \\
\text { massive) }\end{array}$ & \multicolumn{4}{|c|}{ No reference values provided } \\
\hline
\end{tabular}

Abbreviations: RC, rotator cuff; WBC, white blood cell; RBC, red blood cell; PRP, platelet-rich plasma. 
inability to identify if an effective formulation exists. ${ }^{36,37}$ We, therefore, suggest that future studies should focus on reporting their formulations and application processes in order to obtain a better understanding of its potential benefits.

\section{Scaffolds: ECM vs Synthetics}

There has been an evolving role for the use of Extracellular Matrix (ECM) scaffolds and synthetic scaffolds to biologically enhance the intrinsic healing potential and mechanically reinforce surgical repair of the tendon to bone interface, respectively. ECMs are biologic scaffolds derived from fascia lata and decellularized mammalian tissues, such as dermis and small intestine submucosa, and can be classified as allografts or xenografts. Synthetic scaffolds are composed of many different types of polymers, such as polypropylene, poly-L-lactic acid, polycarbonate polyurethane, polycaprolactone, and polydioxanone. ${ }^{38}$ Both types of scaffolds can be used for either augmentation (onlay) of a reparable large to massive tear $^{39}$ or bridging (interposition) of an irreparable tear. ${ }^{40}$ Xenografts, specifically porcine small intestine submucosa, have fallen out of favor over the last decade due to $20-30 \%$ of patients in clinical trials developing a hypersensitive immune response, ${ }^{41,42}$ and no significant differences found in structural failure and outcomes when used in augmented vs nonaugmented controls. ${ }^{43}$

Most recently, acellular human dermal collagen allografts, a type of extracellular matrix scaffold, have become popular for augmenting or bridging large and massive rotator cuff tears. These grafts lack cellular components, which minimize the risk of a host inflammatory response and allow for an active remodeling of organized tissue. ${ }^{44}$ In a two-tendon posterosuperior rotator cuff tear cadaveric study by Van der Meijden et al, the collagen scaffold augmentation was biomechanically superior to single-row repairs and equivalent to extended, linked double-row repairs. ${ }^{10}$ Barber et al published one of the few Level I studies on human acellular dermal allografts and studied patients undergoing arthroscopic repair of 2 tendon rotator cuff tears greater than $3 \mathrm{~cm}$. The use of acellular dermal allograft showed a retear rate in $15 \%$ of the augmented repairs vs $60 \%$ in the nonaugmented controls $(\mathrm{p}<0.01)$ on MRI at greater than 12 months follow up. ${ }^{45}$ Two casecontrol studies also showed a statistically significant decrease in retear rates with acellular dermal allograft augmentation. ${ }^{46,47}$ In revision repair of 13 shoulders with massive posterosuperior tears, Petri et al found an ASES score improvement of 21.5 points, with no patients requiring further surgery at mean 2.5 -year follow-up. ${ }^{48}$ In other retrospective case series on large and massive tears, failure rates for acellular dermal allografts are between $10 \%$ and $40 \%$, with all showing improved clinical outcomes compared to preoperative evaluation. ${ }^{48-53}$ Furthermore, in a systematic review of different types of scaffolds, D'Ambrosi et al found that allografts had the lowest retear rate $(16.4 \%){ }^{54}$

Synthetic scaffolds are advantageous for their mechanical strength and decreased risk of disease transmission. However, they pose a higher risk of bio-incompatibility as they can induce foreign body reactions that lead to infection, decreased stability, synovitis, osteolysis, and osteoarthritis. ${ }^{55}$ To date, limited human studies exist documenting the durability of synthetic scaffolds for augmentation, and most have utilized different combinations of polymers. The only comparative study to date, a 3-year cohort in massive tears, compared a polypropylene synthetic graft augmented open repair to repair augmented with a collagen patch and a repair only group. At 12 months, the retear rate was $17 \%$ for the synthetic patch, $41 \%$ for repair only, and $51 \%$ for the collagen augmented repair. At 36 months, patients treated with a polypropylene patch compared with both groups had statistically significant increases in UCLA scores, abduction strength, and elevation. ${ }^{56}$ Proctor et al utilized a poly-L-lactic acid synthetic patch to treat 18 patients with large to massive rotator cuff tears. Ultrasound showed that 15 of 18 patients had intact rotator cuff repair at 12 months, and 14 intact at 42 months, with ASES scores improving from 25 preoperatively to 71 at 12 months postop ( $\mathrm{p}=0.03){ }^{57}$

Recent systematic reviews have looked at healing rates for various scaffolds in augmentation versus bridging repair. Steinhaus et al conducted a meta-analysis on 24 studies of large to massive tears and concluded that retear rates may be lower with the bridging technique compared to augmentation when performed in patients with ECM and synthetic scaffolds. Xenografts were the most inferior in clinical and functional outcomes and had the highest retear rates. ${ }^{58}$ Ono et al conducted a systematic review in large to massive tears and found the bridging group had a $77.9 \%$ healing rate compared to $64 \%$ in the augmentation group, which was not significant. The authors concluded that inferior healing in the augmentation group might be because augmentation is not capable of altering the inherently high tension of the repair. ${ }^{59}$ 
One possible way to improve healing of the rotator cuff is to augment synthetic scaffolds with biological factors, such as bone marrow-derived stem cells. This combines the mechanical stability provided by synthetic polymers ${ }^{39}$ and the release of chemical signals to induce tissue regeneration that are provided by stem cells. ${ }^{60}$ Yokoya et al compared a polyglycolic acid (PGA) graft seeded with autologously cultured mesenchymal stem cells (MSC) with a PGA sheet alone. In the MSC group at 16 weeks, they found a higher ratio of type I to type III collagen and superior tensile strength in regenerated tendons. ${ }^{61}$ This technique shows extraordinary promise given the benefits synthetic and biological components each have shown separately, and future research should focus on human studies to prove that an integrated scaffold is worthy of consideration.

Superior capsule reconstruction (SCR) is another promising direction of graft reconstruction that is being increasingly used to treat irreparable rotator cuff tears. In this technique, the graft is attached medially to the superior glenoid tubercle, instead of the tendon stump to reconstruct the superior capsule of the shoulder and prevent superior escape of the humeral head. In one of the early biomechanical studies on the technique, Mihata et al showed that SCR provided greater superior stability than the traditional methods of bridging where the graft was connected from the torn supraspinatus tendon to the greater tuberosity. ${ }^{62}$ Further studies using autologous fascia lata graft of 6-8 $\mathrm{mm}$ thickness by the same group have shown excellent healing rates. In their first study of 23 patients, they found $83.3 \%$ of patients had no graft tears or retears of the repaired rotator cuff tendon at a mean follow up of 34.1 months. Also, ASES score improved significantly in patients with healing versus patients who had retears $(\mathrm{p}<0.0001){ }^{63}$ A more recent study by the same group found healing in 95 of 100 patients, significant preop to postop improvements in mean ASES score (36 to 92), and high rates of return to sport and physical work. ${ }^{64}$ Dermal allografts, which can potentially avoid donor site morbidity experienced with autologous fascia lata, have also shown promising results in the United States. Using $3 \mathrm{~mm}$ thick dermal allografts, Lacheta et al found a significant improvement in all clinical outcomes, with graft integrity rates of $100 \%$ (21 of 21 patients) on the tuberosity side, 76\% (16 of 21 patients) at the midsubstance, and $81 \%$ ( 17 of 21 patients) on the glenoid side. No significant differences in clinical outcome scores $(\mathrm{P}>0.930)$ were found in patients with intact grafts versus those with torn grafts. ${ }^{65}$ Denard et al showed a $45 \%$ healing rate at 1 year postoperative MRI and $18.6 \%$ of patients underwent a revision procedure. ${ }^{66} \mathrm{In}$ 86 patients, Pennington et al used $3 \mathrm{~mm}$ thick grafts and reported an increase in ASES score from 52 to 82, and an increase in mean acromiohumeral distance of $7.1 \mathrm{~mm}$ to $9.7 \mathrm{~mm}$ postoperatively. ${ }^{67}$ Based on the slightly inferior results reported in the US, the thickness of the graft may have a large effect on clinical outcomes and healing optimization, but its effect at this time is unknown.

It should be noted that in comparing the biochemical properties of synthetic and biologic scaffolds (Table 2), none match the native supraspinatus tendon. ${ }^{68}$ Though there are issues that still remain, such as the optimal construct, the correct indication, and efficacy, both ECM and synthetic scaffolds, as well as SCR can be used, especially in situations where native tendon is compromised, and additional mechanical augmentation is needed.

\section{Stem Cells}

In the last few years, there has been a proliferation of research concerning cell-based therapies to improve tendon healing. Bone marrow-derived stem cells (BMSCs) and adipose-derived stem cells (ADSCs) are two types of mesenchymal stem cells (MSCs) that have been the primary focus of preclinical studies. Due to their ability to

Table 2 Summary of Scaffolds

\begin{tabular}{|c|c|}
\hline Scaffold & Summary of Literature \\
\hline \multicolumn{2}{|l|}{ ECM } \\
\hline Xenografts & $\begin{array}{l}\text { Porcine small intestine submucosa xenograft } \\
\text { unsafe due to severe inflammatory reactions } \\
\text { reported in high quality studies; }{ }^{41,42} \text { Inferior } \\
\text { clinical and structural results reported in } \\
\text { meta-analyses }{ }^{58,59}\end{array}$ \\
\hline $\begin{array}{l}\text { Acellular Human } \\
\text { Dermal Allograft }\end{array}$ & $\begin{array}{l}\text { Significantly improves retear rates and } \\
\text { improves outcomes scores in high level } \\
\text { studies when used for augmentation of large } \\
\text { and massive tears }{ }^{45-48}\end{array}$ \\
\hline \multicolumn{2}{|l|}{ Synthetics } \\
\hline Polypropylene & $\begin{array}{l}\text { Significantly improves retear rates compared } \\
\text { to repair alone }\end{array}$ \\
\hline Poly-L-lactic acid & $\begin{array}{l}\text { High healing rates and significantly improves } \\
\text { outcomes }^{57}\end{array}$ \\
\hline
\end{tabular}

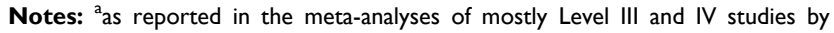
Steinhaus et al and Ono et al. 
become tenocytes, chondrocytes, osteoblasts, and produce growth factors, MSCs have the potential to increase the regeneration of the enthesis and improve the strength and quality of the repair. ${ }^{69}$ The repair of massive tears in particular is usually compromised by chronic lesions with advanced fatty degeneration and atrophy and it is in this realm that MSCs have shown the greatest healing potential. Sevivas et al injected MSC secretomes (paracrine factors) into a rodent model with induced 2-tendon massive rotator cuff tears and found that MSCs showed a reduction of muscle fatty degeneration and atrophy, with more reproducible results in single local injection compared to multiple systemic injections. ${ }^{70}$ Similar results were replicated with ADSCs in rodent models with simulated chronic subscapularis tears ${ }^{71}$ and chronic massive tears. $^{72}$ While these studies show that stem cells could possibly be effective in augmenting repair, they also indicate promise as a conservative treatment.

Additional literature on the histology and biomechanics of BMSCs and ADSCs have been studied in animal models with success, ${ }^{73-76}$ but human studies thus far have been limited, especially in large and massive tears. In a human study with the longest follow-up in the literature, Hernigou et al evaluated 10-year results of 90 patients who underwent single-row repair augmented with BMSCs vs a matched control group without augmentation. At 10 years, 87\% of patients in the BMSC group had intact rotator cuffs compared to $44 \%$ in the control group; ${ }^{77}$ however, this study only looked at rotator cuff tears of 1.5 to $2.5 \mathrm{~cm}$. No human trials utilizing ADSC augmented full-thickness repairs exist, but the first human study using ADSCs alone, a doseescalation trial for the treatment of partial-thickness tears, showed that the volume of articular and bursal side defects decreased by $83 \%$ and $90 \%$ in the mid and high dose groups, respectively. ${ }^{78}$ To our knowledge, no human studies on the effect of BMSCs and ADSCs involving large and massive tears have been published.

A new source of mesenchymal stem cells, those obtained from the subacromial bursae, are now also a subject of interest. In one study, these cells demonstrated strong chondrogenic, adipogenic, and osteogenic potential similar to BMSCs as evidenced by histological, immunohistochemical and PCR analyses. ${ }^{79}$ When pretreated with bone morphogenetic protein-12 (BMP-12), bursal cells expressed markers of tenocytes, and when seeded in ceramic scaffolds, they formed extensive bone and tendon-like tissue. ${ }^{80}$ Although the subacromial bursa is typically identified as a source of pain and discarded as medical waste during arthroscopic surgery, early studies show promise for its ability to improve the healing potential of rotator cuff tears. $^{81}$

If MSCs are applied to augment the repair of large and massive tears, healing efficacy will likely depend on the chronicity, ie fatty degeneration and muscle atrophy, and size of the defect. Equally important to their efficacy will be the way in which MSCs are harvested, processed, and prepared. According to the International Society for Cellular Therapy statement in 2006, researchers use different methods of isolation and expansion of MSCs, and different approaches to characterizing the cells, making it difficult to compare and contrast study outcomes. Standardized reporting measures would thus decrease the regulatory ambiguity and hopefully expand the conditions for use. $^{82}$ As it currently stands, BMSCs and ADSCs are low-risk and not subject to strict regulation by the FDA if they undergo minimal manipulation, are for homologous use only, are not combined with a drug or device, and are autologous or used in a first-degree or second-degree blood relative.

\section{Conclusions}

PRP, scaffolds, and stem cells can potentially improve clinical outcomes by enhancing the healing environment after repair of large and massive tears. PRP has been the most studied and shows decreased retear rates compared to controls in some high-quality studies. However, whether there is any difference in outcomes between repairs augmented with PRP vs no augmentation remains to be determined. We believe that the inconsistencies in results are due to the variability in PRP preparation and administration used across studies. For scaffolds, evidence has become clearer on the inferiority of existing porcine small intestine submucosa xenografts due to their hypersensitive immune responses and equivalent outcomes and healing rates to repair alone. ECMs, specifically acellular human dermal allografts, can decrease retear rates and improve clinical outcomes when used to augment or bridge repairs of large and massive rotator cuff tears. Synthetic scaffolds have been much less studied, but in retrospective studies, their increase in healing and short-term outcomes can be attributed to their durability. A future area of scaffold research concerns a combination, ie a scaffold coated with MSCs, which may prove useful in human therapies. Cellular augmentation with MSCs alone could prove to be therapeutic due to the secretion of numerous growth factors, 
Table 3 Author Grades of Recommendation for Biologics

\begin{tabular}{|l|l|l|l|l|l|l|}
\hline & PRP & $\begin{array}{l}\text { Dermal Allograft } \\
\text { Scaffold }\end{array}$ & $\begin{array}{l}\text { Synthetic } \\
\text { Scaffold }\end{array}$ & $\begin{array}{l}\text { Xenograft } \\
\text { Scaffold }\end{array}$ & $\begin{array}{l}\text { Superior Capsule } \\
\text { Reconstruction }\end{array}$ & $\begin{array}{l}\text { Mesenchymal } \\
\text { Stem Cells }\end{array}$ \\
\hline $\begin{array}{l}\text { Large and Massive } \\
\text { Rotator Cuff Repair }\end{array}$ & Grade C & Grade B & Grade I & $\begin{array}{l}\text { Not } \\
\text { recommended }\end{array}$ & Grade C & Grade I \\
\hline
\end{tabular}

Notes: Grade A indicates good evidence (Level I studies with consistent findings) for or against recommending intervention. Grade B indicates fair evidence (Level II or III studies with consistent findings) for or against recommending intervention. Grade $C$ indicates conflicting or poor-quality evidence (Level IV or $V$ studies) not allowing a recommendation for or against intervention. Grade I indicates that there is insufficient evidence to make a recommendation.

Abbreviation: PRP, platelet-rich plasma.

cytokines, and vesicles conducive to healing, but human studies are lacking and the clinical benefit is unknown.

In summary, patients with large and massive rotator cuff tears have great potential to benefit from biologics if an optimal formula is found. Future prospective highquality studies are needed in order to better define the role of the biologics mentioned in this article. Perhaps a combination of scaffold, PRP, and stem cells, used temporally during the treatment process could provide the greatest improvement in healing and outcomes. Until additional studies are published, we recommend the following based on the given data (Table 3). Due to mixed results in RCTs and meta-analyses, usage of PRP as an adjunct to rotator cuff repair in this patient population cannot be recommended at this time. Acellular dermal allografts are preferred over synthetic scaffolds due to a greater amount of published human studies. They should be used in situations where native tendon is compromised and additional mechanical augmentation is needed. Early studies from SCR report a wide range of healing rates $(45-95 \%),{ }^{63-66}$ despite increases in clinical outcomes. Stem cells have been the least studied to date and there is insufficient evidence to give a recommendation for their use at this time.

\section{Disclosure}

Disclosures for Dr. Peter J. Millett, MD, MSc

Relevant financial relationships to be discussed, directly or indirectly, referred to or illustrated with or without recognition within this presentation are as follows:

Consultants and Royalties: Arthrex, Inc., Medbridge, Springer Publishing

- Paid consultant for (Arthrex exceeding \$500.00/year) and I receive Royalties from Arthrex for surgical devices I developed.

- To minimize any potential COI with royalties received for products that I help develop with Arthrex and potential bias in reporting my surgical results I work with an independent team of researchers (department of COOR at SPRI) tracking and collecting patient outcomes data. These researchers work with the raw data, compile the study cohorts and analyze the data independently. The researchers then produce reports that are then used to write papers for publication in Orthopaedic medical journals.

1. Stock or Stock options in: VuMedi

2. Research activities supported by the Steadman Philippon Research Institute (SPRI) and Vail Valley Medical Center (VVMC).

- Corporate sponsorships for SPRI: Smith \& Nephew, Arthrex, Siemens, Össur Americas, Inc.

Brandon Goldenberg: Brandon's position and this research was supported by the Steadman Philippon Research Institute, which is a 501(c)(3) non-profit institution supported financially by private donations and corporate support from the following entities: Smith \& Nephew Endoscopy, Inc., Arthrex, Inc., Siemens Medical USA, Ossur Americas, Inc., and Vail Valley Medical Center.

Lucca Lacheta: Dr. Lacheta reports grants from AGA outside the submitted work; and This research was supported by the Steadman Philippon Research Institute, which is a 501(c)(3) non-profit institution supported financially by private donations and corporate support from the following entities: Smith \& Nephew Endoscopy, Inc., Arthrex, Inc., Siemens Medical USA, Ossur Americas, Inc., and Vail Valley Medical Center.

Travis Dekker: Dr. Dekker's position and this research was supported by the Steadman Philippon Research Institute, which is a 501(c)(3) non-profit institution supported financially by private donations and corporate support from the following entities: Smith \& Nephew Endoscopy, Inc., Arthrex, Inc., Siemens Medical USA, Ossur Americas, Inc., and Vail Valley Medical Center.

James Spratt: Dr. Spratt's position and this research was supported by the Steadman Philippon Research Institute, 
which is a 501(c)(3) non-profit institution supported financially by private donations and corporate support from the following entities: Smith \& Nephew Endoscopy, Inc., Arthrex, Inc., Siemens Medical USA, Ossur Americas, Inc., and Vail Valley Medical Center.

Philip Nolte: Dr. Nolte reports grants from AGA outside the submitted work; Research Fellowship is supported by Arthrex; and This research was supported by the Steadman Philippon Research Institute, which is a 501(c)(3) non-profit institution supported financially by private donations and corporate support from the following entities: Smith \& Nephew Endoscopy, Inc., Arthrex, Inc., Siemens Medical USA, Ossur Americas, Inc., and Vail Valley Medical Center.

The authors report no other potential conflicts of interest for this work.

\section{References}

1. Kuzel BR, Grindel S, Papandrea R, Ziegler D. Fatty infiltration and rotator cuff atrophy. J Am Acad Orthop Surg. 2013;21(10):613-623. doi:10.5435/JAAOS-21-10-613

2. Gerber C, Krushell RJ. Isolated rupture of the tendon of the subscapularis muscle. Clinical features in 16 cases. $J$ Bone Joint Surg Br. 1991;73(3):389-394. doi:10.1302/0301-620X.73B3.1670434

3. Kovacevic D, Rodeo SA. Biological augmentation of rotator cuff tendon repair. Clin Orthop Relat Res. 2008;466(3):622-633. doi:10.1007/s11999-007-0112-4

4. Uhthoff HK, Trudel G, Himori K. Relevance of pathology and basic research to the surgeon treating rotator cuff disease. J Orthop Sci. 2003;8(3):449-456. doi:10.1007/s10776-002-0624-5

5. Chung SW, Kim JY, Kim MH, Kim SH, Oh JH. Arthroscopic repair of massive rotator cuff tears: outcome and analysis of factors associated with healing failure or poor postoperative function. Am J Sports Med. 2013;41(7):1674-1683. doi:10.1177/0363546513485719

6. Burkhart SS, Danaceau SM, Pearce CE Jr. Arthroscopic rotator cuff repair: analysis of results by tear size and by repair technique-margin convergence versus direct tendon-to-bone repair. Arthroscopy. 2001;17(9):905-912. doi:10.1053/jars.2001.26821

7. Lo IK, Burkhart SS. Arthroscopic revision of failed rotator cuff repairs: technique and results. Arthroscopy. 2004;20(3):250-267. doi:10.1016/j.arthro.2004.01.006

8. Chona DV, Lakomkin N, Lott A, et al. The timing of retears after arthroscopic rotator cuff repair. J Shoulder Elbow Surg. 2017;26 (11):2054-2059. doi:10.1016/j.jse.2017.07.015

9. Greenspoon JA, Petri M, Warth RJ, Millett PJ. Massive rotator cuff tears: pathomechanics, current treatment options, and clinical outcomes. $J$ Shoulder Elb Surg. 2015;24(9):1493-1505. doi:10.1016/j.jse. 2015.04.005

10. van der Meijden OA, Wijdicks CA, Gaskill TR, Jansson KS, Millett PJ. Biomechanical analysis of two-tendon posterosuperior rotator cuff tear repairs: extended linked repairs and augmented repairs. Arthroscopy. 2013;29(1):37-45. doi:10.1016/j.arthro.2012.07.012

11. Vaishnav S, Millett PJ. Arthroscopic rotator cuff repair: scientific rationale, surgical technique, and early clinical and functional results of a knotless self-reinforcing double-row rotator cuff repair system. $J$ Shoulder Elb Surg. 2010;19(2 Suppl):83-90. doi:10.1016/j. jse.2009.12.012

12. Randelli P, Randelli F, Ragone V, et al. Regenerative medicine in rotator cuff injuries. Biomed Res Int. 2014;2014:129515. doi:10.1155/ $2014 / 129515$
13. Eppley BL, Woodell JE, Higgins J. Platelet quantification and growth factor analysis from platelet-rich plasma: implications for wound healing. Plast Reconstr Surg. 2004;114(6):1502-1508. doi:10.1097/ 01.PRS.0000138251.07040.51

14. Jo CH, Kim JE, Yoon KS, Shin S. Platelet-rich plasma stimulates cell proliferation and enhances matrix gene expression and synthesis in tenocytes from human rotator cuff tendons with degenerative tears. Am J Sports Med. 2012;40(5):1035-1045. doi:10.1177/0363546 512437525

15. Foster TE, Puskas BL, Mandelbaum BR, Gerhardt MB, Rodeo SA. Platelet-rich plasma: from basic science to clinical applications. $\mathrm{Am}$ J Sports Med. 2009;37(11):2259-2272. doi:10.1177/0363546509349921

16. van Buul GM, Koevoet WL, Kops N, et al. Platelet-rich plasma releasate inhibits inflammatory processes in osteoarthritic chondrocytes. Am J Sports Med. 2011;39(11):2362-2370. doi:10.11 $77 / 0363546511419278$

17. Kakudo N, Minakata T, Mitsui T, Kushida S, Notodihardjo FZ, Kusumoto K. Proliferation-promoting effect of platelet-rich plasma on human adipose-derived stem cells and human dermal fibroblasts. Plast Reconstr Surg. 2008;122(5):1352-1360.

18. Sadoghi P, Lohberger B, Aigner B, et al. Effect of platelet-rich plasma on the biologic activity of the human rotator-cuff fibroblasts: A controlled in vitro study. J Orthop Res. 2013;31(8):1249-1253. doi: $10.1002 /$ jor. 22360

19. Ide J, Kikukawa K, Hirose J, et al. The effect of a local application of fibroblast growth factor- 2 on tendon-to-bone remodeling in rats with acute injury and repair of the supraspinatus tendon. J Shoulder Elbow Surg. 2009;18(3):391-398. doi:10.1016/j.jse.2009.01.013

20. Wang H, Keiser JA. Vascular endothelial growth factor upregulates the expression of matrix metalloproteinases in vascular smooth muscle cells: role of flt-1. Circ Res. 1998;83(8):832-840. doi:10.1161/01. RES.83.8.832

21. Warth RJ, Dornan GJ, James EW, Horan MP, Millett PJ. Clinical and structural outcomes after arthroscopic repair of full-thickness rotator cuff tears with and without platelet-rich product supplementation: a meta-analysis and meta-regression. Arthroscopy. 2015;31(2):306-320. doi:10.1016/j.arthro.2014.09.007

22. Pandey V, Bandi A, Madi S, et al. Does application of moderately concentrated platelet-rich plasma improve clinical and structural outcome after arthroscopic repair of medium-sized to large rotator cuff tear? A randomized controlled trial. J Shoulder Elbow Surg. 2016;25 (8):1312-1322. doi:10.1016/j.jse.2016.01.036

23. Jo CH, Shin JS, Lee YG, et al. Platelet-rich plasma for arthroscopic repair of large to massive rotator cuff tears: a randomized, single-blind, parallel-group trial. Am J Sports Med. 2013;41 (10):2240-2248. doi:10.1177/0363546513497925

24. Jo CH, Shin JS, Shin WH, Lee SY, Yoon KS, Shin S. Platelet-rich plasma for arthroscopic repair of medium to large rotator cuff tears: a randomized controlled trial. Am J Sports Med. 2015;43 (9):2102-2110. doi:10.1177/0363546515587081

25. Sundman EA, Cole BJ, Fortier LA. Growth factor and catabolic cytokine concentrations are influenced by the cellular composition of platelet-rich plasma. Am J Sports Med. 2011;39(10):2135-2140. doi: $10.1177 / 0363546511417792$

26. Dragoo JL, Braun HJ, Durham JL, et al. Comparison of the acute inflammatory response of two commercial platelet-rich plasma systems in healthy rabbit tendons. Am J Sports Med. 2012;40 (6):1274-1281. doi:10.1177/0363546512442334

27. Antuna S, Barco R, Martinez Diez JM, Sanchez Marquez JM. Platelet-rich fibrin in arthroscopic repair of massive rotator cuff tears: a prospective randomized pilot clinical trial. Acta Orthop Belg. 2013;79(1):25-30.

28. Chahal J, Van Thiel GS, Mall N, et al. The role of platelet-rich plasma in arthroscopic rotator cuff repair: a systematic review with quantitative synthesis. Arthroscopy. 2012;28(11):1718-1727. doi:10.1016/j. arthro.2012.03.007 
29. Zhang Q, Ge H, Zhou J, Cheng B. Are platelet-rich products necessary during the arthroscopic repair of full-thickness rotator cuff tears: a meta-analysis. PLoS One. 2013;8(7):e69731. doi:10.1371/journal. pone. 0069731

30. Moraes VY, Lenza M, Tamaoki MJ, Faloppa F, Belloti JC. Plateletrich therapies for musculoskeletal soft tissue injuries. Cochrane Database Syst Rev. 2014;4:CD010071.

31. Zhao JG, Zhao L, Jiang YX, Wang ZL, Wang J, Zhang P. Plateletrich plasma in arthroscopic rotator cuff repair: a meta-analysis of randomized controlled trials. Arthroscopy. 2015;31(1):125-135. doi:10.1016/j.arthro.2014.08.008

32. Li X, Xu CP, Hou YL, Song JQ, Cui Z, Yu B. Are platelet concentrates an ideal biomaterial for arthroscopic rotator cuff repair? A meta-analysis of randomized controlled trials. Arthroscopy. 2014;30 (11):1483-1490. doi:10.1016/j.arthro.2014.03.020

33. Vavken P, Sadoghi P, Palmer M, et al. Platelet-rich plasma reduces retear rates after arthroscopic repair of small- and medium-sized rotator cuff tears but is not cost-effective. Am J Sports Med. 2015;43(12):3071-3076. doi:10.1177/0363546515572777

34. Saltzman BM, Jain A, Campbell KA, et al. Does the use of platelet-rich plasma at the time of surgery improve clinical outcomes in arthroscopic rotator cuff repair when compared with control cohorts? A systematic review of meta-analyses. Arthroscopy. 2016;32(5):906-918. doi:10.1016/j.arthro.2015.10.007

35. Mesiha MM, Derwin KA, Sibole SC, Erdemir A, McCarron JA. The biomechanical relevance of anterior rotator cuff cable tears in a cadaveric shoulder model. J Bone Joint Surg Am. 2013;95 (20):1817-1824.

36. Chahla J, Cinque ME, Piuzzi NS, et al. A call for standardization in platelet-rich plasma preparation protocols and composition reporting: a systematic review of the clinical orthopaedic literature. J Bone Joint Surg Am. 2017;99(20):1769-1779. doi:10.2106/JBJS.16.01374

37. LaPrade RF, Dragoo JL, Koh JL, Murray IR, Geeslin AG, Chu CR. AAOS research symposium updates and consensus: biologic treatment of orthopaedic injuries. J Am Acad Orthop Surg. 2016;24(7): e62-e78. doi:10.5435/JAAOS-D-16-00086

38. Ricchetti ET, Aurora A, Iannotti JP, Derwin KA. Scaffold devices for rotator cuff repair. J Shoulder Elbow Surg. 2012;21(2):251-265. doi:10.1016/j.jse.2011.10.003

39. Lenart BA, Martens KA, Kearns KA, Gillespie RJ, Zoga AC, Williams GR. Treatment of massive and recurrent rotator cuff tears augmented with a poly-l-lactide graft, a preliminary study. J Shoulder Elbow Surg. 2015;24(6):915-921. doi:10.1016/j.jse.2014.09.044

40. Modi A, Singh HP, Pandey R, Armstrong A. Management of irreparable rotator cuff tears with the graftjacket allograft as an interpositional graft. Shoulder Elb. 2013;5(3):188-194. doi:10.1111/sae.12021

41. Iannotti JP, Codsi MJ, Kwon YW, Derwin K, Ciccone J, Brems JJ. Porcine small intestine submucosa augmentation of surgical repair of chronic two-tendon rotator cuff tears. A randomized, controlled trial. $J$ Bone Joint Surg Am. 2006;88(6):1238-1244. doi:10.2106/ 00004623-200606000-00010

42. Walton JR, Bowman NK, Khatib Y, Linklater J, Murrell GA. Restore orthobiologic implant: not recommended for augmentation of rotator cuff repairs. J Bone Joint Surg Am. 2007;89(4):786-791.

43. Bryant D, Holtby R, Willits K, et al. A randomized clinical trial to compare the effectiveness of rotator cuff repair with or without augmentation using porcine small intestine submucosa for patients with moderate to large rotator cuff tears: a pilot study. J Shoulder Elb Surg. 2016;25(10):1623-1633. doi:10.1016/j.jse.2016.06.006

44. Amini MH, Ricchetti ET, Iannotti JP, Derwin KA. An update on scaffold devices for rotator cuff repair. Tech Shoulder Elb Surg. 2017;18(3):101-112. doi:10.1097/BTE.0000000000000122

45. Barber FA, Burns JP, Deutsch A, Labbe MR, Litchfield RB. A prospective, randomized evaluation of acellular human dermal matrix augmentation for arthroscopic rotator cuff repair. Arthroscopy. 2012;28 (1):8-15. doi:10.1016/j.arthro.2011.06.038
46. Yoon JP, Chung SW, Kim JY, et al. Outcomes of combined bone marrow stimulation and patch augmentation for massive rotator cuff tears. Am J Sports Med. 2016;44(4):963-971. doi:10.1177/036354 6515625044

47. Gilot GJ, Alvarez-Pinzon AM, Barcksdale L, Westerdahl D, Krill M, Peck E. Outcome of large to massive rotator cuff tears repaired with and without extracellular matrix augmentation: a prospective comparative study. Arthroscopy. 2015;31(8):1459-1465. doi:10.1016/j. arthro.2015.02.032

48. Petri M, Warth RJ, Horan MP, Greenspoon JA, Millett PJ. Outcomes after open revision repair of massive rotator cuff tears with biologic patch augmentation. Arthroscopy. 2016;32(9):1752-1760. doi:10.10 16/j.arthro.2016.01.037

49. Bond JL, Dopirak RM, Higgins J, Burns J, Snyder SJ. Arthroscopic replacement of massive, irreparable rotator cuff tears using a GraftJacket allograft: technique and preliminary results. Arthroscopy. 2008;24(4):403-409 e401. doi:10.1016/j.arthro.2007. 07.033

50. Wong I, Burns J, Snyder S. Arthroscopic GraftJacket repair of rotator cuff tears. J Shoulder Elbow Surg. 2010;19(2 Suppl):104-109. doi:10.1016/j.jse.2009.12.017

51. Gupta AK, Hug K, Berkoff DJ, et al. Dermal tissue allograft for the repair of massive irreparable rotator cuff tears. Am J Sports Med. 2012;40(1):141-147. doi:10.1177/0363546511422795

52. Narvani AA, Consigliere P, Polyzois I, Sarkhel T, Gupta R, Levy O. "Owl" technique for all-arthroscopic augmentation of a massive or large rotator Cuff Tear with extracellular matrix graft. Arthrosc Tech. 2016;5(4):e717-e724. doi:10.1016/j.eats.2016.02.035

53. Sears BW, Choo A, Yu A, Greis A, Lazarus M. Clinical outcomes in patients undergoing revision rotator cuff repair with extracellular matrix augmentation. Orthopedics. 2015;38(4):e292-e296. doi:10.3928/01477447-20150402-57

54. D’Ambrosi R, Ragone V, Comaschi G, Usuelli FG, Ursino N. Retears and complication rates after arthroscopic rotator cuff repair with scaffolds: a systematic review. Cell Tissue Bank. 2019;20(1):1-10. doi:10.1007/s10561-019-09750-1

55. McCormack RA, Shreve M, Strauss EJ. Biologic augmentation in rotator cuff repair-should we do it, who should get it, and has it worked? Bull Hosp Jt Dis. 2014;72(1):89-96.

56. Ciampi P, Scotti C, Nonis A, et al. The benefit of synthetic versus biological patch augmentation in the repair of posterosuperior massive rotator cuff tears: a 3-year follow-up study. Am J Sports Med. 2014;42(5):1169-1175. doi:10.1177/0363546514525592

57. Proctor CS. Long-term successful arthroscopic repair of large and massive rotator cuff tears with a functional and degradable reinforcement device. J Shoulder Elb Surg. 2014;23(10):1508-1513. doi:10.1016/j.jse.2014.01.010

58. Steinhaus ME, Makhni EC, Cole BJ, Romeo AA, Verma NN. Outcomes after patch use in rotator cuff repair. Arthroscopy. 2016;32(8):1676-1690. doi:10.1016/j.arthro.2016.02.009

59. Ono Y, Davalos Herrera DA, Woodmass JM, Boorman RS, Thornton GM, Lo IK. Graft augmentation versus bridging for large to massive rotator cuff tears: a systematic review. Arthroscopy. 2017;33(3):673-680. doi:10.1016/j.arthro.2016.08.030

60. Derwin KA, Badylak SF, Steinmann SP, Iannotti JP. Extracellular matrix scaffold devices for rotator cuff repair. J Shoulder Elbow Surg. 2010;19(3):467-476. doi:10.1016/j.jse.2009.10.020

61. Yokoya S, Mochizuki Y, Natsu K, Omae H, Nagata Y, Ochi M. Rotator cuff regeneration using a bioabsorbable material with bone marrow-derived mesenchymal stem cells in a rabbit model. Am $J$ Sports Med. 2012;40(6):1259-1268. doi:10.1177/03635465 12442343

62. Mihata T, McGarry MH, Pirolo JM, Kinoshita M, Lee TQ. Superior capsule reconstruction to restore superior stability in irreparable rotator cuff tears: a biomechanical cadaveric study. Am J Sports Med. 2012;40(10):2248-2255. doi:10.1177/0363546512456195 
63. Mihata T, Lee TQ, Watanabe C, et al. Clinical results of arthroscopic superior capsule reconstruction for irreparable rotator cuff tears. Arthroscopy. 2013;29(3):459-470. doi:10.1016/j.arthro.2012.10.022

64. Mihata T, Lee TQ, Fukunishi K, et al. Return to Sports and Physical Work After Arthroscopic Superior Capsule Reconstruction Among Patients With Irreparable Rotator Cuff Tears. Am J Sports Med. 2018;46(5):1077-1083.

65. Lacheta L, Horan MP, Schairer WW, et al. Clinical and imaging outcomes after arthroscopic superior capsule reconstruction with human dermal allograft for irreparable posterosuperior rotator cuff tears: a minimum 2-year follow-up. Arthroscopy. 2020;36 (4):1011-1019. doi:10.1016/j.arthro.2019.12.024

66. Denard PJ, Brady PC, Adams CR, Tokish JM, Burkhart SS. Preliminary results of arthroscopic superior capsule reconstruction with dermal allograft. Arthroscopy. 2018;34(1):93-99. doi:10.1016/ j.arthro.2017.08.265

67. Pennington WT, Bartz BA, Pauli JM, Walker CE, Schmidt W. Arthroscopic superior capsular reconstruction with acellular dermal allograft for the treatment of massive irreparable rotator cuff tears: short-term clinical outcomes and the radiographic parameter of superior capsular distance. Arthroscopy. 2018;34(6):1764-1773. doi:10. 1016/j.arthro.2018.01.009

68. Smith RDJ, Zargar N, Brown CP, et al. Characterizing the macro and micro mechanical properties of scaffolds for rotator cuff repair. J Shoulder Elbow Surg. 2017;26(11):2038-2046. doi:10.1016/j. jse.2017.06.035

69. Caplan AI. Review: mesenchymal stem cells: cell-based reconstructive therapy in orthopedics. Tissue Eng. 2005;11(7-8):1198-1211. doi:10.1089/ten.2005.11.1198

70. Sevivas N, Teixeira FG, Portugal R, et al. Mesenchymal stem cell secretome: a potential tool for the prevention of muscle degenerative changes associated with chronic rotator cuff tears. Am J Sports Med. 2017;45(1):179-188. doi:10.1177/0363546516657827

71. Oh JH, Chung SW, Kim SH, Chung JY, Kim JY. 2013 Neer Award: effect of the adipose-derived stem cell for the improvement of fatty degeneration and rotator cuff healing in rabbit model. J Shoulder Elbow Surg. 2014;23(4):445-455. doi:10.1016/j.jse.2013.07.054

72. Pauyo T, Rothrauff BB, Chao T, et al. The effect of adipose-derived mesenchymal stem cells on healing of massive chronic rotator cuff tear in rodent model. Orthop J Sports Med. 2017;5(7_supp16). doi:10.1177/2325967117S00375.
73. Chong AK, Ang AD, Goh JC, et al. Bone marrow-derived mesenchymal stem cells influence early tendon-healing in a rabbit achilles tendon model. J Bone Joint Surg Am . 2007;89(1):74-81. doi:10.2106/ 00004623-200701000-00011

74. Gulotta LV, Kovacevic D, Ehteshami JR, Dagher E, Packer JD, Rodeo SA. Application of bone marrow-derived mesenchymal stem cells in a rotator cuff repair model. Am J Sports Med. 2009;37 (11):2126-2133. doi:10.1177/0363546509339582

75. Kida Y, Morihara T, Matsuda K, et al. Bone marrow-derived cells from the footprint infiltrate into the repaired rotator cuff. J Shoulder Elbow Surg. 2013;22(2):197-205. doi:10.1016/j.jse.2012.02.007

76. Chen HS, Su YT, Chan TM, et al. Human adipose-derived stem cells accelerate the restoration of tensile strength of tendon and alleviate the progression of rotator cuff injury in a rat model. Cell Transplant. 2015;24(3):509-520. doi:10.3727/096368915X686968

77. Hernigou P, Flouzat Lachaniette CH, Delambre J, et al. Biologic augmentation of rotator cuff repair with mesenchymal stem cells during arthroscopy improves healing and prevents further tears: a case-controlled study. Int Orthop. 2014;38(9):1811-1818. doi:10.1007/s00264-014-2391-1

78. Jo CH, Chai JW, Jeong EC, et al. Intratendinous injection of autologous adipose tissue-derived mesenchymal stem cells for the treatment of rotator cuff disease: a first-in-human trial. Stem Cells. 2018;36(9):1441-1450. doi:10.1002/stem.2855

79. Steinert AF, Kunz M, Prager P, et al. Characterization of bursa subacromialis-derived mesenchymal stem cells. Stem Cell Res Ther. 2015;6:114. doi:10.1186/s13287-015-0104-3

80. Song N, Armstrong AD, Li F, Ouyang H, Niyibizi C. Multipotent mesenchymal stem cells from human subacromial bursa: potential for cell based tendon tissue engineering. Tissue Eng Part A. 2014;20 (1-2):239-249.

81. Lhee SH, Jo YH, Kim BY, et al. Novel supplier of mesenchymal stem cell: subacromial bursa. Transplant Proc. 2013;45(8):3118-3121. doi:10.1016/j.transproceed.2013.07.052

82. Piuzzi NS, Hussain ZB, Chahla J, et al. Variability in the preparation, reporting, and use of bone marrow aspirate concentrate in musculoskeletal disorders: a systematic review of the clinical orthopaedic literature. J Bone Joint Surg Am. 2018;100(6):517-525. doi:10. 2106/JBJS.17.00451
Orthopedic Research and Reviews

\section{Publish your work in this journal}

Orthopedic Research and Reviews is an international, peer-reviewed, open access journal that focusing on the patho-physiology of the musculoskeletal system, trauma, surgery and other corrective interventions to restore mobility and function. Advances in new technologies, materials, techniques and pharmacological agents are particularly

\section{Dovepress}

welcome. The manuscript management system is completely online and includes a very quick and fair peer-review system, which is all easy to use. Visit http://www.dovepress.com/testimonials.php to read real quotes from published authors. 